\title{
Tardigrade Exposure to Outer Space Conditions - An Experimental Validation
}

\author{
Vasanthan $\mathrm{T}^{1,2}$, Lubberdink $\mathrm{A}^{1}$ and Stone $\mathbf{J}^{1,2^{*}}$ \\ ${ }^{1}$ Department of Biology, McMaster University, 1280 Main Street West, Hamilton ON L8S 4K1, Canada \\ ${ }^{2}$ Origins Institute, McMaster University, 1280 Main Street West, Hamilton ON L8S 4M1, Canada
}

"Corresponding author: Jonathon Stone, Associate Director, Origins Institute, Department of Biology, McMaster University, 1280 Main Street West, Hamilton ON L8S 4K1, Canada, Tel: +905-525-9140; Fax: 905-922-6066; E-mail: jstoner@mcmaster.ca

Received date: Oct 1, 2014, Accepted date: Oct 29, 2014, Published date: Oct 31, 2014

Copyright: (c) 2014 Vasanthan T, et al. This is an open-access article distributed under the terms of the Creative Commons Attribution License, which permits unrestricted use, distribution, and reproduction in any medium, provided the original author and source are credited.

\begin{abstract}
Researchers have identified and used regions characterized by extreme environmental conditions on Earth as analogue sites for conducting astrobiological experiments. Researchers also have simulated extreme environmental conditions in laboratory settings. Whether data obtained at analogue sites or in laboratory settings would be similar to data obtained extraterrestrially is unknown because opportunities for comparison occur very rarely. We realized such an opportunity by replicating a 'bioexposure' experiment that was conducted recently in Earth orbit. Tardigrades (Phylum Tardigrada - extreme-tolerant, microscopic invertebrate animals) exposed to desiccation and radiation treatment combinations in a laboratory setting yielded survivorship curves similar to survivorship curves yielded in 2007 by Tardigrades exposed to outer space conditions in the BIOPAN facility aboard the FOTON-M3 spacecraft. This constitutes the first direct comparison demonstrating that data acquired extraterrestrially can be replicated in a laboratory setting on Earth, validating Earth- based, laboratory setting research.
\end{abstract}

Keywords: Astrobiology; Desiccation tolerance; Extreme environment; Life science; Radiation tolerance; Tardigrade.

\section{Introduction}

The potential for organisms to survive exposure to outer space conditions depends on their abilities to tolerate extremely low pressures (i.e., vacuum), temperatures (i.e., freezing), and humidities (i.e., desiccation) and high radiation (i.e., solar and cosmic) levels. Tardigrades are the only animals to have survived exposure to outer space conditions, during their journey aboard the FOTON-M3 spacecraft [1] We herein briefly review the morphological and molecular characteristics that suit tardigrades as ideal organisms for astrobiological research and describe an experiment that we conducted to determine whether survivorship curves acquired extraterrestrially from the FOTON-M3 mission can be replicated terrestrially in a controlled, terrestrial laboratory setting.

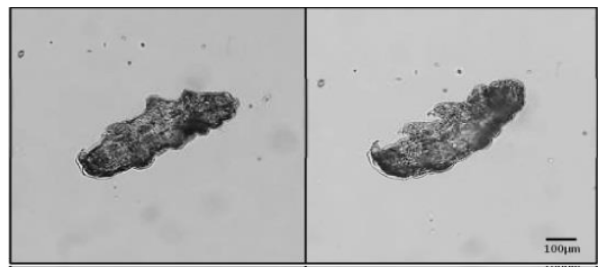

Figure 1: A Macrobiotus harmsworthii specimen viewed dorsally (left) and laterally (right).

\section{Tardigrade Biology}

The Tardigrada, literally 'slow walkers,' is a phylum that contains microscopic panarthropod species, known colloquially as 'water bears.' Tardigrades inhabit environments ranging from marine to freshwater to semi-terrestrial, in a planet-wide distribution [2-6]. Tardigrade morphologies are characterized by elongated, bilaterally symmetric bodies (ranging typically from $0.25 \mathrm{~mm}$ to $1.0 \mathrm{~mm}$ in length) including four trunk segments, a head segment with eyes, and four paired stublike lobopod legs that terminate distally in claws or digits [7] [Figure 1]. The phylum is categorized into two extant classes, Eutardigrada and Heterotardigrada, containing more than 1000 species $[7,8]$

The phylum is renowned for the tolerance exhibited by member species. In response to exposure to extreme conditions, individuals in some tardigrade species enter a characteristic 'cryptobiotic' state, in which metabolic activity effectively ceases (at least at measureable levels). This ametabolic configuration is referred to as the 'tun' state and its onset is accompanied by morphological changes - invagination (i.e., limbs), infolding (i.e., cuticle), and contraction (i.e., body) similar to contraction in wheel animals (i.e., rotifers) [9] and coiling in roundworms (i.e., nematodes) [10].

\section{Tardigrade Freeze Tolerance}

As observed in other organisms, tardigrades upregulate stress molecules, such as 'antifreeze' proteins, which lower freezing points, and ice nucleating agents, which promote ice formation extracellularly (reducing osmotic shock), to minimize detrimental effects in response to extreme freezing [11-13]. That ice nucleating agents comprise proteins and lipoproteins was demonstrated by heating some individuals prior to inducing them to enter the tun state; the temperature at which ice formation initiated was lower in heated than control groups, presumably as a consequence from denaturation at elevated temperatures [14].

Additionally, nonreducing compounds, such as 'freeze-drying' sugars like trehalose, replace water around cellular macromolecules, vitrifying media and preventing intracellular damage [15-17]. Trehalose levels, however, typically are lower in tardigrades than they are in other freeze-tolerant taxa [14]. In response to experimental 
freezing below crystallization temperatures, $80-90 \%$ total body water froze to ice in individuals in two Arctic tardigrade species [13]. Extracellular ice may provide support to internal organ systems, averting the need to enter the tun state for freeze tolerance (entering the tun state is required for desiccation tolerance, whereupon water content is reduced drastically) [18]. Survivorship is enhanced if individuals enter the tun state gradually, in response to slow cooling (e.g., $-1^{\circ} \mathrm{C} \mathrm{hr-1)} \mathrm{[19].} \mathrm{Active} \mathrm{metabolism} \mathrm{is} \mathrm{necessary} \mathrm{for} \mathrm{tun}$ formation; slow cooling presumably allows time for cryoprotectants to accumulate [20]. During freezing, the phase change from water to ice can cause cellular damage [21]. Tardigrades that were induced experimentally to enter the tun state incurred single strand breaks to their DNA, and these damages increased with trehalose destruction induced by oxidative stress and high temperatures [22].

Tardigrades can tolerate extreme freezing in hydrated or dehydrated states $[14,20,23]$ Freezing in a hydrated state imposes a greater risk than does freezing in a dehydrated state; dehydrated individuals thus tend to survive freezing more effectively than do hydrated individuals. In a comparative analysis involving hydrated and dehydrated individuals in three tardigrade species maintained at $-22^{\circ} \mathrm{C},-80^{\circ} \mathrm{C}$ and $-180^{\circ} \mathrm{C}$, survivorship was lowest among hydrated individuals, suggesting that freezing in a hydrated state incurs a higher cost to longevity than does freezing in a dehydrated state and freezing temperatures might have preservation effects that are amplified in desiccative conditions [23].

Species that are very successful at tolerating extremely low temperatures were found to be very successful at tolerating extremely low humidities. Freshwater and semiaquatic species, including the one used for the research described herein, the eutardigrade Hypsibius dujardini, are unadapted to desiccation and generally less successful at surviving extreme freezing [24].

\section{Tardigrade Desiccation Tolerance}

As they do with freeze tolerance, tardigrades synthesize protective compounds such as trehalose to protect anatomical structures from damage during desiccation tolerance $[19,25,26]$. Individuals in the species Richtersius coronifer produced 2.3 dry weight trehalose during desiccation, reaching a maximum 48 hours after entering the tun state [16]. Tardigrades such as $R$. coronifer contain relatively low trehalose levels relative to other desiccation tolerant organisms, such as the arthropod species Artemia salina (cysts) and Polypedilum vanderplanki. Trehalose production is species specific; individuals in the species Milensium tardigradum synthesize no trehalose [27] and trehalose accumulation has yet to be observed in the class Heterotardigrada [28], for instances. This suggests that other compounds play protective roles in response to desiccation. Consistent with this suggestion, wax secretions added to outer cuticle surfaces minimize transpiration, allowing tardigrades to retain up to $15 \%$ total body water [23].

Also as with freeze tolerance, survivorship is enhanced if individuals are allowed to synthesize compounds gradually, in response to slow desiccation. Anesthetized tardigrades are unable to enter the tun state when desiccated and die; similar to the situation with freeze tolerance, slow desiccation presumably allows time for elevated compound levels to accumulate. Survivorship additionally is enhanced if individuals experience desiccation at high relative humidities (i.e., $>70 \%$ ) [19,27]. Rapid desiccation warps tardigrade bodies into irregular shapes, and individuals typically fail to revive upon rehydration $[3,19]$. Hengherr et al. [27] showed that individuals that were subjected to alternating hydrated- and dehydrated-feeding regimes exhibited active longevities similar to individuals that were reared in hydrated (i.e., control) conditions, in the tardigrade species Milnesium tardigradum. This demonstrates that individuals in that tardigrade species incur no costs in surviving desiccative conditions. Desiccated tardigrades have been documented to have survived experimentally up to 8 years in the tun state [24,28], apocryphally up to a century $[29,30]$.

\section{Tardigrade Radiation Tolerance}

Initial research on radiation tolerance in tardigrades revealed an association with humidity. May et al. observed that dehydrated individuals survived much longer UV radiation exposures than did hydrated individuals in the species Macrobiotus areolatus, with a lethal-dose 50\% (LD50) value exceeding $5 \mathrm{kGy}$ for both groups [31]. Later research revealed that the association is nonuniversal among tardigrade species. Hydrated and dehydrated individuals in Richtersius coronifer [32,33,] and Melnesium tardigradum [34] exhibit similar survivorship after exposure to ionizing radiation.

Jönsson et al. studied $\gamma$ radiation effects on life history and survival for individuals in hydrated (0.5-5 kGy) and dehydrated (1-9 kGy) states in the eutardigrade species Richtersius coronifer. Dehydrated and hydrated groups irradiated with 1 and $0.5 \mathrm{kGy}$ yielded survivorship curves that were similar to control group survivorship curves. Hydrated groups irradiated with 2 kGy yielded morepronounced mortality 5-10 days post revival; with $3 \mathrm{kGy}$ yielded steeply increasing mortality a few days post exposure; and with $4 \mathrm{kGy}$ and $5 \mathrm{kGy}$ exhibited little viability and only subtle leg movements; one tardigrade irradiated at $7 \mathrm{kGy}$ showed subtle movements after 47 hours. Mortality in dehydrated groups similarly increased with dosage but more gradually than it did in hydrated groups. Decreased egg production occurred as radiation dosage increased, and no eggs produced by irradiated tardigrades hatched [32].

Horikawa et al. exposed individuals in the species $M$. tardigradum to a variety of radiation types (e.g., 1.0-7.0 kGy $\gamma$ ray, 1.0-8.0 kGy $4 \mathrm{He}$ heavy ion) and observed that two-day post-irradiation individuals were characterized by $\mathrm{LD} 50=5.0 \mathrm{kGy}$ ( $\gamma$ ray) and $6.2 \mathrm{kGy}$ (heavy ion) in hydrated states and $4.4 \mathrm{kGy}$ ( $\gamma$ ray) and $5.2 \mathrm{kGy}$ (heavy ion) in dehydrated states. Higher gamma radiation doses resulted in shorter life spans in individuals in hydrated and desiccated conditions. All individuals exposed to 2.0-4.0 kGy died within 31 days, whereas some were able to survive exposures up to $1000 \mathrm{~Gy}$ ( $\gamma$ ray). Individuals in hydrated conditions yielded slightly higher survival rates than did individuals in desiccated conditions [34]. Radiation doses greater than $1.0 \mathrm{kGy}$ caused sterility; only a single specimen (exposed to $2.0 \mathrm{kGy} \gamma$ ray) among those irradiated laid eggs (among those eggs, three failed to hatch), whereas non-irradiated individuals laid viable eggs. Horikawa et al. later exposed laboratory-cultured samples in the species Ramazzottius varieornatus to 4000 Gy radiation $\left({ }^{4} \mathrm{He}\right.$ heavy ion), observing approximately $100 \%$ and $90 \%$ survival rate with individuals in hydrated and dehydrated conditions, respectively [35].

Nilsson et al. examined radiation tolerance in $R$. coronifer. Individuals in dehydrated state were exposed to $0.5-15 \mathrm{kGy} 2.55 \mathrm{MeV}$ proton radiation. Individuals were unaffected up to $10 \mathrm{kGy}$ radiation; viability decreased markedly for greater doses. Scanning transmission ion microscopy revealed that dehydrated specimen thicknesses exceeded $150 \mu \mathrm{m}$, the penetration depth for the radiation [33]. 
Altiero et al. exposed individuals in hydrated and dehydrated states in the species Paramacrobiotus richtersi and Ramazzottius oberhaeurseri to 7 UV radiation levels between 10.32 and $87.72 \mathrm{~kJ} \mathrm{~m}^{-2}$ in combination with other stressors, like low temperature. Individuals exhibited impressive survivorship to high radiation level exposure. Remarkably, individuals in hydrated states tolerated extreme conditions more effectively than did individuals in dehydrated states in high-humidity and low- temperature environments [36].

Tardigrades became the first animals to survive exposure to outer space conditions, in 2007. Individuals from two tardigrade species $(M$. tardigradum and R.coronifer) were launched successfully into outer space aboard the European Space Agency (ESA) FOTON-M3 robotic spacecraft, at a low Earth orbit (258-281 km above sea level; Jönsson et al., 2008). Individuals in dehydrated states were exposed to space vacuum alone, space vacuum and UVA-UVB (i.e., 280-400 $\mathrm{nm}$ ), and space vacuum and UVfull (i.e., 116.5-400 nm). All individuals were exposed to ionizing solar and galactic cosmic radiation. Control and vacuum-exposed groups exhibited similar survival rates, whereas UVA-UVB and UVfull-exposed groups exhibited lower survival rates. Among UVA-UVB-exposed individuals, 68\% revived within 30 minutes, but subsequent mortality was high in $M$. tardigradum; one revived in $R$. coronifer. Among $\mathrm{UV}_{\text {full- }}$ exposed individuals, three survived in $M$. tardigradum. We show herein that results earing striking similarity to those obtained in the FOTON-M3 mission can be obtained in an outer space simulation experiment on Earth.

\section{Materials \& Methods}

Specimens in the eutardigrade species Macrobiotus harmsworthii were sampled and collected from moss-living populations retrieved from the forest floor and tree bark in Cootes Paradise, Hamilton, Ontario, Canada. Adult specimens were extracted from moss samples and hydrated for 48 hours at $10^{\circ} \mathrm{C}$ and maintained in $2 \mathrm{~mL}$ culture wells containing $1.5 \mathrm{~mL}$ distilled water and moss sediments.

Throughout a 38-day period, 3 groups containing 35 specimens were exposed to conditions that were analogous to those experienced by tardigrades in the outer space experiment [1]: subjected to desiccation only $(D)$, exposed to $U_{A+B}$ radiation only $\left(U_{A+B}\right.$, 290-390 nm), subjected to desiccation and exposed to $U_{\mathrm{A}+\mathrm{B}}$ radiation $\left(D_{U} V_{A+B}\right)$. Hydrated specimens with added moss sediments were desiccated gradually over a 2 to 4 day period in dark conditions at $10^{\circ} \mathrm{C}$. To replicate the radiation experienced by tardigrades on the FOTON-M3 spacecraft, specimens were exposed to continuous UVA and UVB radiation $(290-390 \mathrm{~nm}$ at $25 \mathrm{~W})$ at $10^{\circ} \mathrm{C}$. A control group (C) containing hydrated specimens was maintained at $10^{\circ} \mathrm{C}$ for comparison. Surviving specimens in the 4 groups were counted periodically and fed algae (Chlorococcum sp. and moss leaflets); water was replenished for surviving specimens in the hydrated groups $(C$ and $\left.\mathrm{UV}_{\mathrm{A}+\mathrm{B}}\right)$ every 2 to 4 days. Counting was conducted every 2 to 4 days at $10^{\circ} \mathrm{C}$ in dark conditions. Animals were considered living if they displayed coordinated leg movements. Data that were obtained were compared to data obtained in the FOTON-M3 mission [1]. Comparisons were conducted with logrank tests supplemented by Bonferroni corrections (whereupon $\alpha=0.0125$ was used as the significance level for 4 post hoc tests).

\section{Results}

Life spans for individuals in the nonirradiated groups (C and D) were extended (mean time, $t=43$ days for both) relative to life spans for individuals in the irradiated groups $\left(\mathrm{UV}_{\mathrm{A}+\mathrm{B}}, \mathrm{t}=22\right.$ days; $\mathrm{DUV}_{\mathrm{A}+\mathrm{B}}, \mathrm{t}=27$ days; $\mathrm{P}<0.125$; Figure 2). Survivorship differed significantly between control and irradiated-desiccated groups $\left(\mathrm{C}\right.$ and $\left.\mathrm{DUV}_{\mathrm{A}+\mathrm{B}} ; \mathrm{P}<0.125\right)$.

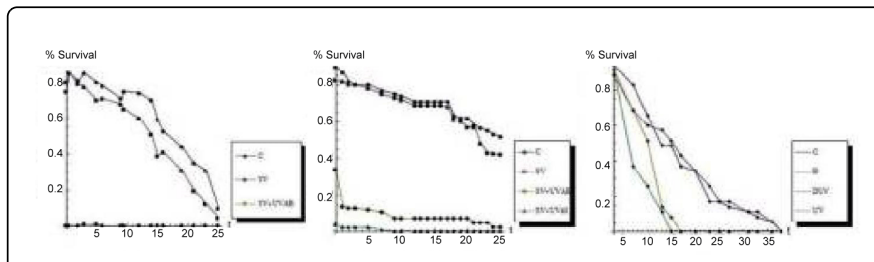

Figure 2: Percent survival for a control group and three treatment groups after tardigrades were subjected to real (left and middle panels) and simulated (right panel) outer space conditions. Real outer space treatments included outer space vacuum (OSV), outer space vacuum and UVA and UVB radiation $\left(\mathrm{OSVUV}_{\mathrm{A}+\mathrm{B}}\right)$, and outer space vacuum and complete range UV radiation (OSVUVALL) [1] simulated outer space treatments included desiccation $(\mathrm{D}), \quad \mathrm{UV}_{\mathrm{A}+\mathrm{B}}$ radiation $\left(\mathrm{UV}_{\mathrm{A}+\mathrm{B}}\right)$, and combined desiccation and $\mathrm{UV}_{\mathrm{A}+\mathrm{B}}$ radiation $(\mathrm{DUVA}+\mathrm{B})$. In the panels, the control group is the topmost plot, followed by: OSV and OSVUVAB for Richtersius coronifer (left); OSV, OSVUV $\mathrm{A}_{\mathrm{A}+\mathrm{B}}$, and OSVUVALL for Milnesium tardigradum (middle); and D, $\mathrm{UV}_{\mathrm{A}+\mathrm{B}}$, and $\mathrm{DUV}_{\mathrm{A}+\mathrm{B}}$ for Macrobiotus harmsworthii (right).

\section{Discussion}

Desiccated individuals exhibited no significant difference in survival compared to control individuals, as in the outer space experiment [1] and desiccated-and- $\mathrm{UV}_{\mathrm{A}+\mathrm{B}}$-exposed individuals exhibited significantly reduced survival.

The outer space experiment constituted the first study designed to test effects from actual radiation exposure on tardigrade survival and involved only desiccated individuals [1]. In our controlled, Earthbased experiment, we were able to test desiccation and radiation effects independently and in combination. Irradiated groups $\left(\mathrm{UV}_{\mathrm{A}+\mathrm{B}}\right.$ and $\left.\mathrm{DUV}_{\mathrm{A}+\mathrm{B}}\right)$ exhibited no differences in survival in later weeks (2-5), but both exhibited reduced survival compared to control groups (C, except in week 1 , when group $\mathrm{DUV}_{\mathrm{A}+\mathrm{B}}$ exhibited no difference relative to group $\mathrm{C}$ ). We conclude that tun formation arising from desiccation confers no defense against $\mathrm{UV}_{\mathrm{A}+\mathrm{B}}$ radiation damage in Macrobiotus harmsworthii.

We recognized a rare opportunity to compare an experiment conducted in outer space to a simulation experiment conducted on Earth. This constitutes the first such comparison, validating using laboratory environments on Earth in astrobiological research [37] and providing the first opportunity to document different effects imparted between analogue sites and their real, extraterrestrial counterparts. An important difference, other than location and species, between the outer space experiment and the experiment reported herein concerns exposure. The outer space experiment involved a relatively acute, high dose exposure (UVA - UVB $>7000 \mathrm{kJm}^{-2}$; realized as $280-400 \mathrm{~nm}$ UVA-UVB in space vacuum and $116.5-400 \mathrm{~nm} \mathrm{UV}_{\text {full }}$ in space vacuum, from 10 days orbit at $258-281 \mathrm{~km}$ above sea level, where $\mathrm{UV}_{\text {full }}$ represents UV from all spectral ranges), whereas ours involved a chronic, relatively low dose exposure (26 W continuous at 290-390 $\mathrm{nm} \mathrm{UV}_{\mathrm{A}+\mathrm{B}}$ for up to 38 days). Even given these three differences, effects on survival were comparable from a qualitative perspective. 
Our results suggest that astrobiologists may conduct experiments on Earth to assess the possibility for contamination extraterrestrially via spacecraft and probes and additionally using organisms for which outer space travel currently is impractical. Researchers must (and now can) start analyzing the quantitative differences between data obtained from Earth-based and extraterrestrial sites, especially identifying the underlying factors.

\section{Acknowledgement}

The Natural Sciences and Engineering Research Council of Canada (Discovery Grant 261590) and The Joseph and Joanne Lee Ontario Graduate Scholarship provided financial grounding for the research.

\section{References}

1. Jönsson KI, Rabbow E, Schill RO, Harms-Ringdahl M, Rettberg P (2008) Tardigrades survive exposure to space in low Earth orbit. Curr Biol 18: R729-729R731.

2. Jørgensen A, Kristensen RM (2004) Molecular phylogeny of Tardigrada-investigation of the monophyly of Heterotardigrada. Mol Phylogenet Evol 32: 666-670.

3. Kinchin IM (1994) The Biology of Tardigrades. Portland Press, London.

4. Nelson DR (2001) Tardigrada, in: Thorp J, Covich A (Eds.), Ecology and Classification of North American Freshwater Invertebrates (2nd edn), Academic Press, San Diego.

5. Nelson DR (2002) Current status of the tardigrada: evolution and ecology. Integr Comp Biol 42: 652-659.

6. Ramazzotti E, Maucci W, (1983) The Phylum Tardigrada (translated by Beasley CW), Memories of the Italian Institute of Hydrobiology Dr. Marco de Marchi, Verbiana-Pallanza.

7. Nelson DR, Marley N (2000) The biology and ecology of lotic Tardigrada. Freshwater Biol 44: 93-108.

8. Romano FA (2003) On water bears. Florida Entomologist. 86: 134-137.

9. Jacobs $\mathrm{MH}$ (1909) The effects of desiccation on the rotifer Philodina roseola. J Exp Zool 6: 207-263.

10. Demeuke Y, Frixkman DW (1981) Recent advances in the study of anhydrobiotic nematodes, in: Zuckerman BM, Mai WF, Rohde RA (Eds.) Plant Parasitic Nematodes.Vol. III. Academic Press, New York.

11. Lee RE Jr, Costanzo JP (1998) Biological ice nucleation and ice distribution in cold-hardy ectothermic animals. Annu Rev Physiol 60: 55-72.

12. Westh P, Kristensen R (1992) Ice formation in the freeze-tolerant eutardigrades Adorybiotus coronifer and Amphibolus nebulosus studied by differential scanning calorimetry. Polar Biol 12: 693-699.

13. Westh P, Kristiansen J, Hvidt A (1991) Ice-nucleating activity in the freeze-tolerant tardigrade Adorybiotus coronifer. Comp Biochem Physiol 99A: 401-404.

14. Westh P, Ramløv H (1991) Trehalose accumulation in the tardigrade Adorybiotus coronifer during anhydrobiosis. J. Exp. Zool. 258: 303-311.

15. Crowe JH, Hoekstra FA, Crowe LM (1992) Anhydrobiosis. Annu Rev Physiol 54: 579-599.

16. Schill RO, Steinbrück GH, Köhler HR (2004) Stress gene (hsp70) sequences and quantitative expression in Milnesium tardigradum (Tardigrada) during active and cryptobiotic stages. J Exp Biol 207: 1607-1613.
17. Neuman Y (2006) Cryptobiosis: a new theoretical perspective. See comment in PubMed Commons below Prog Biophys Mol Biol 92: 258-267.

18. Wright JC, Westh P, Ramløv H (1992) Cryptobiosis in Tardigrada. Biol Rev 61:1-29.

19. Crowe JH (1972) Evaporative water loss by tardigrades under controlled relative humidities. Biol Bull 142: 407-416.

20. Ramløv H, Westh P (1992) Survival of the cryptobiotic eutardigrade Adorybiotus coronifer during cooling to $-196^{\circ} \mathrm{C}$ : Effect of cooling rate, trehalose level, and short-term acclimation. Cryobiol 29: 125-130.

21. Fuller BJ (2004) Cryoprotectants: the essential antifreezes to protect life in the frozen state. See comment in PubMed Commons below Cryo Letters 25: 375-388.

22. Rebecchi L, Cesari M, Altiero T, Frigieri A, Guidetti R (2009) Survival and DNA degradation in anhydrobiotic tardigrades. J Exp Biol 212: 4033-4039.

23. Somme L, Meier T (1995) Cold tolerance in Tardigrada from Dronning Maud Land, Antartica. Polar Biol 15: 221-224.

24. Bertolani R, Guidetti R, Jönsson, KI, Altiero T, Boschini D, et al. (2004) Experiences with dormancy in tardigrades. J Limnol 63:16-25.

25. Higa LM, Womersley CZ (1993) New insights into the anhydrobiotic phenomenon: the effect of trehalose content and differential rates of evaporative water loss on the survival of Aphelenchus avenae. J Exp Zool 267:120-129.

26. Watanabe M, Kikawada T, Fujita A, Adati T, Okuda T (2004) Physiological traits of invertebrates entering cryptobiosis in a postembryonic stage. Eur. J. Entomol. 101: 439-444.

27. Hengherr S, Heyer AG, Köhler HR, Schill RO (2008) Trehalose and anhydrobiosis in tardigrades--evidence for divergence in responses to dehydration. FEBS J 275: 281-288.

28. Guidetti R, Jönsson KI (2002) Long-term anhydrobiotic survival in semiterrestrial micrometazoans. J Zool 257: 181-187.

29. Franceschi T (1948) Anabiosi than tardigradi. Boll Mus Ist Biol Univ Genova 22: 47-49.

30. Jönsson KI, Bertolani R (2001) Facts and fiction about long-term survival in tardigrades. J Zool 255: 121-123.

31. May RM, Maria M, Guimard J (1964) Differential actions of x-rays and ultraviolet on the tardigrade Macrobiotus areolatus in the active state and dried .Bull Biol Fr Belg 98: 349-367.

32. Jönsson KI, Harms-Ringdahl M, Torudd J (2005) Radiation tolerance in the eutardigrade Richtersius coronifer. Int J Radiat Biol 81: 649-656.

33. Nilsson EJ, Jönsson KI, Pallon J (2010) Tolerance to proton irradiation in the eutardigrade Richtersius coronifer--a nuclear microprobe study. Int J Radiat Biol 86: 420-427.

34. Horikawa DD, Kunieda T, Abe W, Watanabe M, Nakahara Y, et al. (2008) Establishment of a rearing system of the extremotolerant tardigrade Ramazzottius varieornatus: a new model animal for astrobiology. Astrobiology 8: 549-556.

35. Horikawa DD, Sakashita T, Katagiri C, Watanabe M, Kikawada T, et al. (2006) Radiation tolerance in the tardigrade Milnesium tardigradum. Int J Radiat Biol 82: 843-848.

36. Altiero T, Guidetti R, Caselli V, Cesari M, Rebecchi L (2011) Ultraviolet radiation tolerance in hydrated and desiccated eutardigrades. J. Zool. Syst Evol Res 49:104-110.

37. McKay CP (1997) The search for life on Mars. Orig Life Evol Biosph 27: 263-289. 